\title{
Root temperature and energy consumption at different cable depths in electrically heated substrates
}

\author{
María Dolores Fernandez*, Manuel Ramiro Rodriguez ${ }^{1}$, Rafael López Pidre ${ }^{1}$, Teresa Teijeiro ${ }^{1}$ \\ ${ }^{1}$ Universidad de Santiago de Compostela / Escuela Politécnica Superior - Depto. Ingeniería Agroforestal - \\ Campus Universitario s/n - 27002 - Lugo, Spain. \\ *Corresponding author <mdolores.fernandez@usc.es> \\ Edited by: Luis Reynaldo Ferracciú Alleoni
}

\begin{abstract}
A finite element method-based model of a substrate heated by an electric heating cable buried in a thermal isolated container was experimentally validated with root mean square error values of root zone temperature ranging 0.25 to $0.62{ }^{\circ} \mathrm{C}$. The two-dimensional transient model allowed variations in the physical properties of the substrate with temperature, water content and depth. The operation of nine configurations of a heating cable buried in sand at different depths (50 to $450 \mathrm{~mm}$, at $50 \mathrm{~mm}$ intervals) at $200 \mathrm{~mm}$ spacing was simulated and assessed. The validated model was used to perform 24-h simulations applying boundary conditions, and substrate moisture content was experimentally obtained at a mean substrate surface temperature of $13.98^{\circ} \mathrm{C}$. Such simulations reproduced the operation of the heating system by setting a reference temperature of $20^{\circ} \mathrm{C}$ at the control point in the root zone. Burying the heating cable in the surface layers of the substrate caused large temperature gradients and high heat losses through the substrate surface. Accordingly, average temperature in the root zone increased with heating cable depth, up to the $200 \mathrm{~mm}$ depth. For greater depths, temperature in the root zone was constant. The ON/OFF control was most effective with the heating cable buried in the root zone and at control point temperatures of $20 \pm 1{ }^{\circ} \mathrm{C}$. Burying the heating cable in the surface layers required higher energy consumption, up to $28 \%$ at $50 \mathrm{~mm}$. The most efficient heating cable depth was $350 \mathrm{~mm}$, with a daily energy consumption of 6750 $\mathrm{kJ} \mathrm{m}{ }^{-2}$.

Keywords: FEM model, heat consumption, heating systems, soil heating
\end{abstract}

\section{Introduction}

Root zone temperatures within a range of $18{ }^{\circ} \mathrm{C}$ to $24{ }^{\circ} \mathrm{C}$ are suggested for the development of plants (Roper et al., 2004; Gent and Ma, 2000; Dodd et al., 2000; Mortesen and Gislerod, 1996). Substrate heating systems should be capable of guaranteeing the preset temperatures for each substrate layer according to crop requirements.

Models of localized heating systems for growing substrates have been developed and assessed. Some of these models use warm air (Boulard et al., 1989a,b; Kurpaska and Slipek, 1996), warm water (Ahmed et al., 1983; Kurpaska and Slipek, 2000), or electric cables (Fernandez et al., 2005 a,b; De La Plaza et al., 1999; Rikbost et al., 1975; Rodriguez et al., 2004). The high cost of the energy supply demands maximum energy efficiency of the heating system. Heating cable (HC) spacing is one of the technical parameters that most affect the energy consumption of the heating system (Fernandez and Rodriguez, 2006; Fernandez et al., 2007). Likewise, choosing the appropriate HC depth may entail significant energy savings and changes in the distribution of temperatures affecting the plant.

Our objective is to analyze the effects on root zone temperature (0-150 $\mathrm{mm}$ depth) and energy consumption of the depth of installation of an electric HC buried at different depths in a sandy substrate without compromising production. To this end, it is necessary to: (i) ensure the reliable simulation of the operation of the $\mathrm{HC}$ by providing data of energy consumption and substrate temperature - for this purpose, the Finite Element Method (FEM)-based model proposed by Fernandez and Rodriguez (2006), which allows for the simulation of substrate heating systems, is experimentally validated; (ii) analyze the spatial and temporal distribution of temperatures in the root zone, the effectiveness of the control system, and the energy consumption for the operation of nine heating systems with different HC installation depths. Data were obtained from 24 h-simulations performed under identical environmental conditions and thermal requirements.

\section{Materials and Methods}

The devised experimental test made it possible to obtain: (i) boundary conditions to apply to the model, (ii) data of substrate moisture at different depths, and (iii) data for model validation. We arranged a $230 \mathrm{~V}$ AC-fed parallel HC, $30 \mathrm{~W}$ per meter of cable, with silicone insulation (Model AKO - 5234, AKO, Barcelona, Spain) into a container built with a sandwich panel structure with a core of extruded polystyrene foam (Figure 1). The $\mathrm{HC}$ was buried at the $225 \mathrm{~mm}$ depth and at a 100 and $150 \mathrm{~mm}$ spacing. The volumetric water content of the substrate was maintained at a range of $0.10-0.14$ by means of an irrigation system. Lower water content values were obtained at the thin surface layer $(10 \mathrm{~mm})$ due to desiccation. The irrigation system was made up of 12 microsprinklers, $20 \mathrm{~L} \mathrm{~h}^{-1}$, with an effective diameter of $1200 \mathrm{~mm}$, working pressure of $200 \mathrm{kPa}$, located at a height of $300 \mathrm{~mm}$ above substrate surface.

Inside the container, sand substrate with a mean geometric diameter of $379 \mathrm{~mm}$ was arranged. The solid den- 
sity of the substrate was $2,686 \mathrm{~kg} \mathrm{~m}^{-3}$, and the average bulk density of the dry substrate was $1,256 \mathrm{~kg} \mathrm{~m}^{-3}$, variable in depth. Negative thermal coefficient thermistor temperature sensors (Models Campbell 107 and Campbell 108, Campbell Sci. Ltd, Loughborough, UK) and matric potential sensors (Model Watermark 257, Delta-T Devices Ltd, Cambridge, UK), with porous matrix and measurement range $0-200 \mathrm{kPa}$ and $5 \mathrm{~V}$ AC excitation were placed at different substrate locations (Figure 1). Sensors collected data related to these variables for the operation of the heating and irrigation systems. The HC operation system aimed at maintaining a mean temperature of $20^{\circ} \mathrm{C}$ in the root zone. The $\mathrm{HC}$ was switched on when the probe located at position T1, buried $150 \mathrm{~mm}$ (Figure 1), showed temperature values below $25{ }^{\circ} \mathrm{C}$, and it was switched off when the probe showed values equal to or higher than 25 ${ }^{\circ} \mathrm{C}$. These operation conditions achieved a mean temperature of $20.2^{\circ} \mathrm{C}$ at position $\mathrm{T} 1$, buried $75 \mathrm{~mm}$ in the middle of the root zone.

Measurements were taken by temperature and soil moisture probes at 1 min intervals. The mean values were stored at $15 \mathrm{~min}$ intervals using a data logger (Model CR10X, Campbell Sci. Ltd, Loughborough, UK). The data logger was connected to a programmable control-
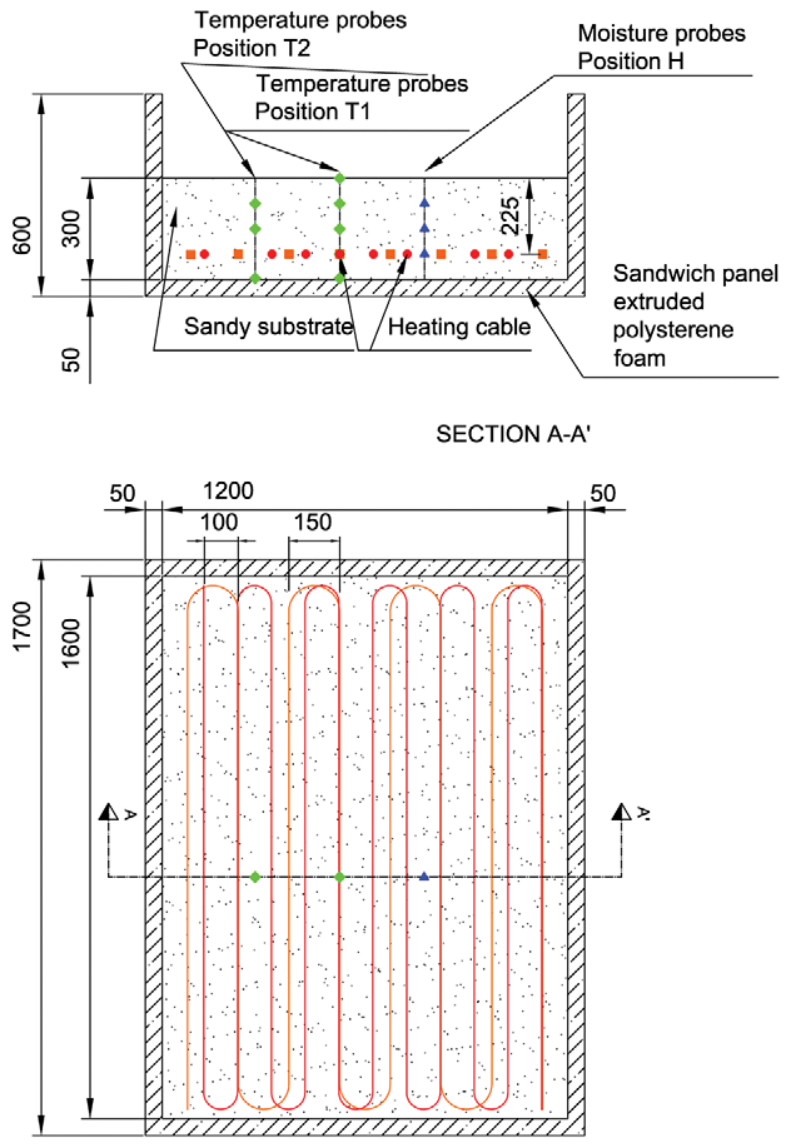

PLAN

Figure 1 - Components and arrangement of the substrate heating cable system. Position of temperature probes and position of soil moisture probes. ler (Model S7-200, Siemens AG, München, Germany) that controlled the systems according to received data.

The analysis presented in this paper is based on the model suggested by Fernandez and Rodriguez (2006), which was developed with the general-purpose code ANSYS v 6.0. Such a model allowed the thermal analysis of electric cable heating systems for substrates in a two-dimensional space and in a transient state. The model consisted of various programming modules:

Parameterization of geometric and thermal variables - In this module, the properties of the materials and the geometric variables that defined the system were determined. The main difficulty for simulation was the soil, insofar as the soil is a discontinuous medium (Jury et al., 1991). However, the use of the methods by De Vries (1963) for the estimation of the volumetric heat capacity $\left(C_{v}\right)$ and Campbell et al. (1994) for the estimation of effective thermal conductivity $\left(k_{e}\right)$ allowed us to consider the soil as a continuous medium. The value of $C_{v}$ was dependent on water content, and $k_{e}$ was additionally dependent on temperature. The thermal properties of the soil were estimated as a function of texture, temperature and water content (Table 1).

Generation of the geometry - The geometry was generated in a two-dimensional space, taking a section perpendicular to the heating cable at a midpoint of the container (Figure 1). Two geometries were defined. One reproduced the dimensions of the experimental test and was used for validation. A second geometry allowed for the analysis of different depths. Thus, the depths of the second geometry were greater than the depths considered in the first one. In the second geometry, substrate dimensions were 1,600 $\mathrm{mm}$ width by $500 \mathrm{~mm}$ depth, divided into $50 \mathrm{~mm}$-deep layers. To obtain a better definition of the surface layer, the surface layer was divided into two distinct parts of 10 and $40 \mathrm{~mm}$.

Meshing and shape function - The generated meshes were rectangular, regular, and composed of 3,451 nodes in the validation geometry and 3,104 nodes in the simulation geometry. The mesh was denser at the surface of the substrate. The shape function that determined the physical behavior of each element was defined by the Law of conservation of energy that regulates heat flow in a solid medium, restricted to the mechanisms of conduction and convection. When referred to a differential control volume, rep-

Table 1 - Thermal properties of the analyzed substrate layers.

\begin{tabular}{ccccccc}
\hline \multirow{2}{*}{$\mathrm{d}^{(\mathrm{a})}$} & \multirow{2}{*}{$\mathrm{D}_{\mathrm{b}}^{(\mathrm{b})}$} & $\theta^{(\mathrm{c})}$ & $\mathrm{C}_{\mathrm{v}}^{(\mathrm{d})}$ & & \multicolumn{3}{c}{$\mathrm{k}_{\mathrm{e}}^{(e)}$} \\
\cline { 5 - 8 } & & & & $10{ }^{\circ} \mathrm{C}$ & $30^{\circ} \mathrm{C}$ & $60{ }^{\circ} \mathrm{C}$ \\
\hline $0-10$ & 1137 & 0.07 & 740.2 & 0.62 & 0.66 & 0.87 \\
\hline $10-200$ & 1137 & 0.14 & 1030.7 & 0.83 & 0.87 & 1.04 \\
\hline $300-300$ & 1230 & 0.12 & 983.9 & 0.89 & 1.93 & 1.12 \\
$400-500$ & 1300 & 0.11 & 990.7 & 0.96 & 1.00 & 1.21 \\
\hline
\end{tabular}

${ }^{\mathrm{a}} \mathrm{d}=$ depth in $\mathrm{mm} \cdot{ }^{\mathrm{b}} \mathrm{D}_{\mathrm{b}}=$ bulk density in $\mathrm{kg} \mathrm{m}^{-3} \cdot{ }^{\mathrm{c}} \theta=$ water content in $\mathrm{m}^{3} \mathrm{~m}^{-3} \cdot{ }^{\mathrm{d}} \mathrm{C}_{\mathrm{v}}=$ heat capacity in $\mathrm{kJ} \mathrm{m}^{-3}{ }^{\circ} \mathrm{C}^{-1} \cdot{ }^{\mathrm{e}} \mathrm{k}_{\mathrm{e}}=$ effective thermal conductivity in $\mathrm{W} \mathrm{m}^{-1}{ }^{\circ} \mathrm{C}^{-1}$. 
resented in the two-dimensional model as an area (ANSYS, 2001), the law of conservation of energy is written as:

$$
C_{v}\left(\frac{\partial T}{\partial t}\right)+\left(\{L\}^{T}\left(-\left[\mathbf{K}_{\mathrm{e}}\right]\{L\} T\right)\right)=r_{H s}
$$

where: $C_{v}$ is volumetric heat capacity in $\mathrm{J} \mathrm{m}^{-3}{ }^{\circ} \mathrm{C}^{-1} ; T$ is temperature in ${ }^{\circ} \mathrm{C} ; t$ is time in $\mathrm{s} ;\{L\}$ is the differential operator; $\left[K_{e}\right]$ is the effective thermal conductivity matrix of a porous medium, which includes the effects of conduction and convection in $\mathrm{W} \mathrm{m}{ }^{-1}{ }^{\circ} \mathrm{C}^{-1}$; and $r_{H s}$ is the rate of generation of heat per volume unit of soil in $\mathrm{W} \mathrm{m}^{-3}$.

Static analysis conducted to obtain the initial conditions - The boundary conditions were: temperature at the substrate surface and two hypothetical temperatures, the uniform temperature of the substrate as a whole and the temperature of the heating cable. The $\mathrm{HC}$ temperature was gradually increased up to $20^{\circ} \mathrm{C}$ at the root zone. The static analysis provided a temperature distribution in the heated substrate that was introduced as initial boundary conditions for the transient analysis.

Parameterization of boundary conditions and times of analysis - The time step was $15 \mathrm{~min}$, whereas the time substep was $1 \mathrm{~min}$. Based on the experimental test, values were applied at each step of analysis to initial temperature at every node and to temperature at the substrate surface according to Eq. 2. The daily mean temperature of the substrate surface was $13.98{ }^{\circ} \mathrm{C}$. The heat that flows at the heating cable position was specified at each step of the analysis.

Application of boundary conditions and solution The transient thermal analysis required:

(i) Establishment of the initial conditions based on the results of the static analysis.

(ii) Application of temperatures at the surface of the substrate and application of the heat flow emitted by the electric heating cable at each step of analysis. The heat flow must be introduced sequentially according to the operational conditions aimed at maintaining a mean temperature of $20^{\circ} \mathrm{C}$ in the root zone. The cable was switched on when temperature in the root zone was under $20{ }^{\circ} \mathrm{C}$ and the temperature of the heating cable was under 55 ${ }^{\circ} \mathrm{C}$ and it was switched off when temperature in the root zone reached $20^{\circ} \mathrm{C}$, or when the temperature of the heating cable reached $55^{\circ} \mathrm{C}$. Heat exchange between the system and the environment was allowed. The variation of boundary conditions between steps of analysis was considered as linear.

(iii) Solution of the model. The temperatures of each node and of the heat flow on each element at each substep of analysis were obtained using the Newton-Raphson algorithm. The maximum number of iterations allowed at each substep was 15 , a value that was not exceeded in order to achieve equilibrium conditions. The tolerance values for temperatures and heat flows were established at $10^{-3}{ }^{\circ} \mathrm{C}$ and $10^{-6}$ $\mathrm{W} \mathrm{m} \mathrm{m}^{-2}$, respectively.

\section{Results and Discussion}

Validation of the model - The simulation model was validated by comparing the results obtained from the model with experimental data. To this end, the operation of two configurations of a heating system was simulated for $24 \mathrm{~h}$. The dimensions of the heating system matched the dimensions of the system used in the experimental test. Two geometries were tested, with the HC buried at $225 \mathrm{~mm}$ depth and at 100 and $150 \mathrm{~mm}$ spacing. Table 2 summarizes the validation results, which contrast the temperatures at different depths, both at the vertical of the heating cable (T1) and at an average distance between cables ('T2).

Generally, the simulations in the root zone (0 to $150 \mathrm{~mm}$ depth) are acceptable, with values of Root Mean Square Error between 0.25 and $0.62{ }^{\circ} \mathrm{C}$. Near the heating cable $(300$ $\mathrm{mm}$ depth), errors show higher values, with a maximum value of $1.32{ }^{\circ} \mathrm{C}$, which is in agreement with the values of the average temperatures reached at these depths. Nor-

Table 2 - Statistics estimated for two transient simulations of the operation of heating cable located at $225 \mathrm{~mm}$ depth, during 24 hours.

\begin{tabular}{|c|c|c|c|c|c|c|c|}
\hline \multirow{2}{*}{$\begin{array}{l}\text { Spacing } \\
\mathrm{Mm}\end{array}$} & \multirow{2}{*}{$\frac{\text { Statistic }}{{ }^{\circ} \mathrm{C}}$} & \multicolumn{3}{|c|}{ Position $\mathrm{T} 1^{(\mathrm{e})}$ at the depths } & \multicolumn{3}{|c|}{ Position $T 2^{(\mathrm{f})}$ at the depths } \\
\hline & & $75 \mathrm{~mm}$ & $150 \mathrm{~mm}$ & $300 \mathrm{~mm}$ & $75 \mathrm{~mm}$ & $150 \mathrm{~mm}$ & $300 \mathrm{~mm}$ \\
\hline \multirow{4}{*}{100} & $\mathrm{~T}_{\mathrm{ma}}(\mathrm{a})$ & 21.17 & 25.03 & 28.69 & 20.64 & 23.94 & 26.63 \\
\hline & $\mathrm{AE}^{(\mathrm{b})}$ & 0.36 & -0.17 & -0.67 & 0.60 & 0.44 & 0.34 \\
\hline & $\mathrm{SDE}^{(c)}$ & 0.02 & 0.08 & 0.28 & 0.03 & 0.09 & 0.39 \\
\hline & $\mathrm{RMSE}^{(\mathrm{d})}$ & 0.38 & 0.34 & 0.85 & 0.62 & 0.53 & 0.71 \\
\hline \multirow{4}{*}{150} & $\operatorname{Tm} a^{(a)}$ & 20.18 & 24.99 & 29.94 & 19.69 & 24.82 & 28.62 \\
\hline & $\mathrm{AE}^{(\mathrm{b})}$ & -0.24 & -0.49 & -1.27 & 0.22 & -0.46 & -0.82 \\
\hline & $\mathrm{SDE}^{(\mathrm{c})}$ & 0.01 & 0.09 & 0.11 & 0.02 & 0.04 & 0.21 \\
\hline & $\operatorname{RMSE}^{(\mathrm{d})}$ & 0.26 & 0.57 & 1.32 & 0.25 & 0.50 & 0.94 \\
\hline
\end{tabular}

${ }^{a} \mathrm{~T}_{\mathrm{ma}}$ : Average temperature measured at the corresponding depth. ${ }^{\mathrm{b}} \mathrm{AE}$ : Average Error or bias. ${ }^{\mathrm{c} S D E}$ : Standard deviation of the error. ${ }^{\mathrm{d}}$ RMSE: Root Mean Square Error. ${ }^{\mathrm{m}}$ Position T1: at the vertical of the heating cable. ${ }^{\mathrm{f}}$ Position T2: on the axis of the spacing between cables. 
mally, the temperatures used to control the heating system are found in the root zone, where the simulation is more accurate. In addition, the accuracy of simulation in this zone is similar to or higher than the sensitivity of most sensors.

The experimentally measured values of energy consumption were 11.88 and $9.72 \mathrm{MJ}$ for HC spacings of 100 and $150 \mathrm{~mm}$, respectively, whereas simulations required 12.96 and $10.08 \mathrm{MJ}$, which involves an overestimation of energy consumption of $9.1 \%$ and $3.7 \%$ for HC spacings of 100 and $150 \mathrm{~mm}$. Energy consumption estimation errors are reasonable and are in agreement with temperature overestimations.

Periods of simulation - We tested the performance of an electric heating cable buried at nine depths in the range 50 to $450 \mathrm{~mm}$, at $50 \mathrm{~mm}$ intervals and at a fixed spacing of $200 \mathrm{~mm}$. To determine the simulation period, we defined the following criterion in order to ensure that the heat supplied by the heating cable compensated for heat losses through the soil surface: the difference between the average temperature of the whole substrate at the beginning of the day and the average temperature of the whole substrate at the end of the day must be below $\pm 0.5^{\circ} \mathrm{C}$. To meet this criterion, we simulated the operation of the cable for periods ranging from 24 to $72 \mathrm{~h}$, depending on the configuration of the heating system. Table 3 summarizes the number of days simulated and the differences in daily temperatures for each depth. A 24-h period was analyzed for each heating system, regardless of the length of the simulated period.

Effects of HC temperature on the root zone - The main study area is the root zone because this zone is essential for root growth and development. The bottom layers are essential for heat storage, but temperature at such layers does not directly affect the crop, although the heat that comes up from the bottom layers indirectly affects the crop. Accordingly, our analysis focuses on temperatures at depths of 50, 100, 150 and $200 \mathrm{~mm}$. Daily average temperature in the root zone is calculated as the mean of the temperatures obtained at the vertical coordinate of the HC (T1) and on the axis of the spacing between cables (T2). In addition, we analyzed the following temperatures because of their influence on heating system control: temperature at the substrate surface (T-00), HC temperature, and temperature at the $70 \mathrm{~mm}$ depth and at the $50 \mathrm{~mm}$ horizontal spacing from the $\mathrm{HC}$ (T-70), which acts as a control point at $20{ }^{\circ} \mathrm{C}$ preset temperature.
Three behaviors related to HC installation depth were observed, with a similar evolution and distribution of temperatures in the root zone, and a similar operation of the HC: (1) HC buried at the 50 to $150 \mathrm{~mm}$ depths with a depth/spacing ratio (d/s) lower than 1; (2) HC buried at the $200 \mathrm{~mm}$ depth with a d/s of 1; and (3) $\mathrm{HC}$ buried at the 250 to $450 \mathrm{~mm}$ depth with a d/s greater than 1 .

HC buried at the 50 to $150 \mathrm{~mm}$ depth - The temperatures obtained in the root zone for a depth of installation of the $\mathrm{HC}$ of $50 \mathrm{~mm}$ are very uniform, around $20^{\circ} \mathrm{C}(19.6$ ${ }^{\circ} \mathrm{C}$ ), except for the HC temperature (Figure 2). All the temperatures observed in the root zone follow the trend of the evolution of the HC. With the increase in $\mathrm{HC}$ depth, the evolution described for the HC depth of $50 \mathrm{~mm}$ is maintained, with a clear loss of spatial and temporal uniformity of temperatures (Figures 2 and 3). The temperature of the $\mathrm{HC}$ increases with $\mathrm{HC}$ depth, with a consequent increase in the temporal fluctuation of substrate temperatures. In addition, temperatures in the root zone increase and the differences between temperatures at various depths become sharper.

With the increase in the $\mathrm{HC}$ depth, the heat losses through the substrate surface decrease. During the analyzed period, the operation period of the $\mathrm{HC}$ amounts to $16 \mathrm{~h}$ at the 50 $\mathrm{mm}$ HC depth and decreases to $13 \mathrm{~h}$ at the 100 and 150 $\mathrm{mm}$ depths. With the increase in room temperature, $\mathrm{ON}$ cycles of the $\mathrm{HC}$ become shorter. Moreover, the highest frequencies of the $\mathrm{ON}$ cycles were observed for $\mathrm{HC}$ depths of 50 and $100 \mathrm{~mm}$. The operation of the heating cable becomes increasingly irregular with increase in depth, both in terms of length and frequency of the ON periods. For a HC buried at the $50 \mathrm{~mm}$ depth, the heating cable experiences 14 complete ON/OFF cycles, with an average length of 69 minutes for the ON cycles (Figure 2). By increasing the HC depth up to $100 \mathrm{~mm}$, a total of $15 \mathrm{ON} / \mathrm{OFF}$ cycles with a mean length of 52 minutes are observed. At a HC depth of 150 $\mathrm{mm}$, the ON/OFF cycles of cable decrease to 9. The length of the $\mathrm{ON}$ periods ranges from $30 \mathrm{~min}$ to $3 \mathrm{~h} 30 \mathrm{~min}$, with an average value of $1 \mathrm{~h} 27 \mathrm{~min}$, and are dependent mainly upon room temperature (Figure 3).

HC buried at $200 \mathrm{~mm}$ - The increase in the HC depth brings about an important change in the operation of the system (Figure 4). In addition, the mean temperature of the root zone increases again up to $21.8{ }^{\circ} \mathrm{C}$ as a consequence of

Table 3 - Analyzed depths, simulation period and differences in the average temperature of the whole substrate at the beginning and at the end of each day.

\begin{tabular}{|c|c|c|c|c|c|c|c|c|c|c|c|c|c|c|c|c|c|}
\hline \multicolumn{3}{|c|}{$\mathrm{d}^{(\mathrm{b})}=50$} & \multicolumn{2}{|c|}{$\mathrm{d}^{(\mathrm{b})}=100$} & \multicolumn{2}{|c|}{$\mathrm{d}^{(\mathrm{b})}=150$} & \multicolumn{2}{|c|}{$\mathrm{d}^{(\mathrm{b})}=200$} & \multicolumn{2}{|c|}{$\mathrm{d}^{(\mathrm{b})}=250$} & \multicolumn{2}{|c|}{$\mathrm{d}^{(\mathrm{b})}=300$} & \multicolumn{2}{|c|}{$\mathrm{d}^{(\mathrm{b})}=350$} & \multicolumn{2}{|c|}{$\mathrm{d}^{(\mathrm{b})}=400$} & \multirow{2}{*}{$\frac{\mathrm{d}^{(\mathrm{b})}=450}{\mathrm{~T}_{\mathrm{ad}}{ }^{(\mathrm{c})} \Delta \mathrm{T}^{(\mathrm{d})}}$} \\
\hline$t^{(a)}$ & $\mathrm{T}_{\mathrm{ad}}(\mathrm{c})$ & $\Delta \mathrm{T}^{(\mathrm{d})}$ & $\mathrm{T}_{\mathrm{ad}}{ }^{(\mathrm{c})}$ & $\Delta \mathrm{T}^{(\mathrm{d})}$ & $\mathrm{T}_{\mathrm{ad}}{ }^{(\mathrm{c})}$ & $\Delta T^{(\mathrm{d})}$ & $\mathrm{T}_{\mathrm{ad}}{ }^{(\mathrm{c})}$ & $\Delta \mathrm{T}^{(\mathrm{d})}$ & $\mathrm{T}_{\mathrm{ad}}{ }^{(\mathrm{c})}$ & $\Delta \mathrm{T}^{(\mathrm{d})}$ & $\mathrm{T}_{\mathrm{ad}}{ }^{(\mathrm{c})}$ & $\Delta \mathrm{T}^{(\mathrm{d})}$ & $\mathrm{T}_{\mathrm{ad}}(\mathrm{c})$ & $\Delta T^{(\mathrm{d})}$ & $\mathrm{T}_{\mathrm{ad}}(\mathrm{c})$ & $\Delta \mathrm{T}^{(\mathrm{d})}$ & \\
\hline 0 & 20.0 & & 21.8 & & 24.4 & & 26.9 & & 29.0 & & 30.8 & & 31.9 & & 32.6 & & 33.1 \\
\hline 24 & 19.7 & 0.3 & 21.3 & 0.5 & 23.4 & 0.9 & 25.0 & 1.9 & 25.9 & 3.0 & 26.8 & 4.0 & 27.4 & 4.5 & 27.8 & 4.9 & 27.4 \\
\hline 48 & - & - & 21.2 & 0.1 & 23.3 & 0.2 & 24.9 & 0.1 & 26.0 & -0.1 & 26.9 & -0.1 & 27.5 & -0.1 & 27.9 & -0.2 & 28.0 \\
\hline 72 & & & - & - & & - & - & - & - & - & - & - & - & - & - & - & 28.1 \\
\hline
\end{tabular}

${ }^{a} \mathrm{t}=$ time in $\mathrm{h} .{ }^{\mathrm{b}} \mathrm{d}=$ depth in $\mathrm{mm} .{ }^{\mathrm{c}} \mathrm{T}_{\mathrm{ad}}=$ average daily temperature of the whole substrate. ${ }^{\mathrm{d}} \Delta \mathrm{T}=$ daily increase in substrate temperature. 
the increase of the HC temperature. Likewise, the vertical temperature gradients increase. The operation time of the $\mathrm{HC}$ is $13 \mathrm{~h}$. The frequency of operation of the system decreases dramatically (two complete ON/OFF cycles) and the length of the $\mathrm{ON}$ periods increases up to an average value of $6.5 \mathrm{~h}$ (Figure 4). Artificial heat supply is not necessary at higher room temperatures, which suggests that the deep layers of the substrate contribute to maintaining the temperature in the root zone because of the insulation layer under the substrate.

HC buried at depths between 250 and $450 \mathrm{~mm}$ - Conversely to the previous cases, the average temperature in the root zone decreases slightly down to values from $21.5^{\circ} \mathrm{C}$ (at $250 \mathrm{~mm}$ HC depth) to $21.6{ }^{\circ} \mathrm{C}$ (at $350 \mathrm{~mm}$ HC depth). Such a decrease is caused by the new locations of the cable in deeper substrate layers, out of the root zone. The increase in HC temperature is related to the increase in the temperature gradients in the root zone (Figure 5). The operation of the cable is reproduced in the root zone, but very attenuated. We observed some delay in the achievement of root zone tempera-

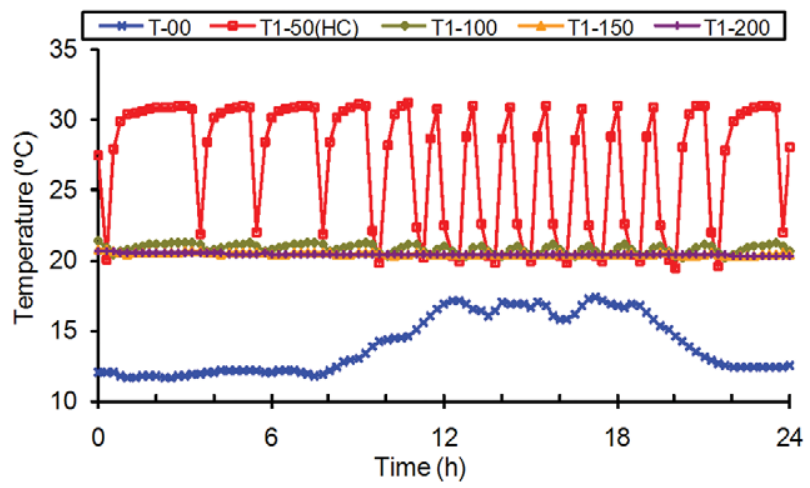

Figure 2 - Temperatures at the surface of the substrate (T-00) and at the vertical of the $\mathrm{HC}$ (position T1) at $50 \mathrm{~mm}$ (T150), $100 \mathrm{~mm}$ (T1-100), $150 \mathrm{~mm}$ (T1-150) and $200 \mathrm{~mm}$ (T1-200) depths for the configuration with the HC buried at $50 \mathrm{~mm}$ depth.

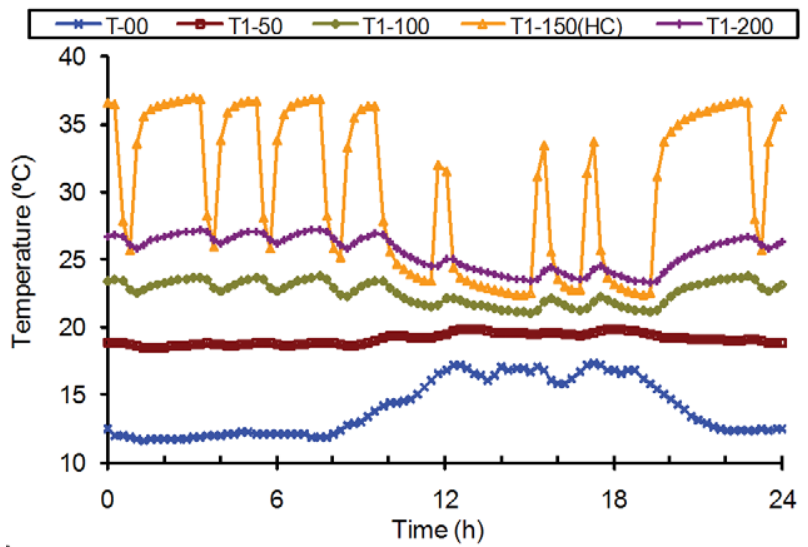

Figure 3 - Temperatures at the surface of the substrate (T-00) and at the vertical of the HC (position T1) at $50 \mathrm{~mm}$ (T150), $100 \mathrm{~mm}$ (T1-100), $150 \mathrm{~mm}$ (T1-150) and $200 \mathrm{~mm}$ (T1-200) depths for the configuration with the HC buried at $150 \mathrm{~mm}$ depth. tures as compared to $\mathrm{HC}$ temperatures and a great uniformity in the horizontal distribution of temperatures.

The times of operation of the HC during the analyzed day range from $12.5 \mathrm{~h}$ (at $350 \mathrm{~mm} \mathrm{HC}$ depth) to $13.25 \mathrm{~h}$ (at 300 and $400 \mathrm{~mm}$ HC depths), as in the previous configuration. In all the cases, there is one cycle of operation. The HC is continuously switched on during the periods with low surface temperatures $\left(16.7-12.4^{\circ} \mathrm{C}\right)$. With the increase in $\mathrm{HC}$ depth, the switching on and off is delayed.

Analysis of the HC control - To analyze temperatures at the control point (T-70), the maximum, mean, minimum and standard deviation values have been calculated for each depth (Table 4). The level of achievement of the reference temperature at the control point has been defined as the percentage of time that temperature at T-70 is maintained in the

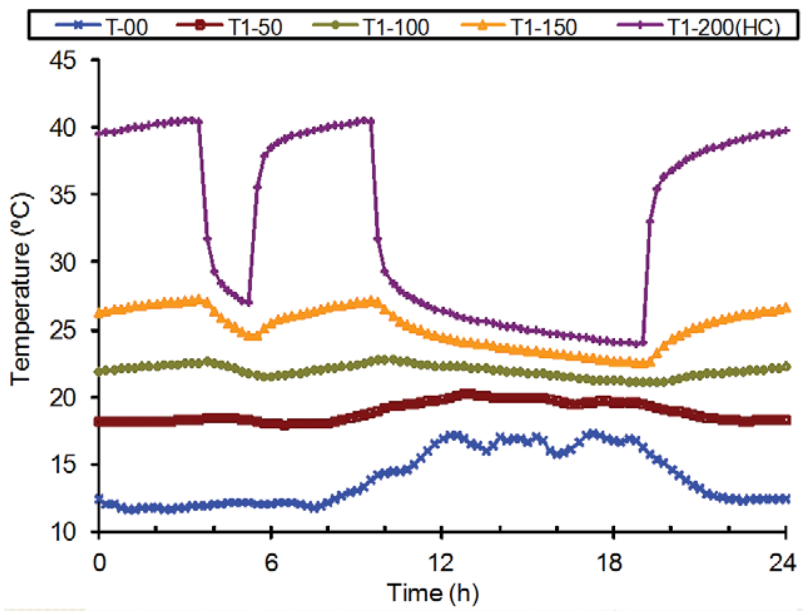

Figure 4 - Temperatures at the surface of the substrate (T-00) and at the vertical of the $\mathrm{HC}$ (position T1) at $50 \mathrm{~mm}$ (T150), $100 \mathrm{~mm}$ (T1-100), $150 \mathrm{~mm}$ (T1-150) and $200 \mathrm{~mm}$ (T1-200) depths for the configuration with the HC buried at $200 \mathrm{~mm}$ depth.

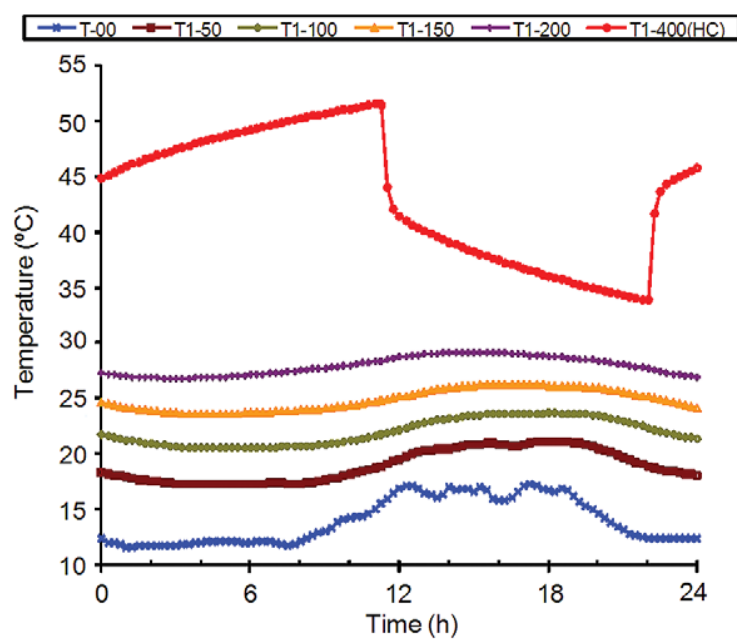

Figure 5 - Temperatures at the surface of the substrate (T-00) and at the vertical of the HC (position T1) at $50 \mathrm{~mm}$ (T150), $100 \mathrm{~mm}$ (T1-100), $150 \mathrm{~mm}$ (T1-150) and $200 \mathrm{~mm}$ (T1-200) depths for the configuration with the HC buried at $400 \mathrm{~mm}$ depth. 
Table 4 - Maximum, minimum and mean values, standard deviation and level of temperature achievement by the control point (T-70) at different HC depths.

\begin{tabular}{|c|c|c|c|c|c|c|c|c|c|}
\hline & & & & & $\mathrm{d}_{\mathrm{HC}}^{(\mathrm{a})}$ & & & & \\
\hline & 50 & 100 & 150 & 200 & 250 & 300 & 350 & 400 & 450 \\
\hline $\mathrm{T}_{\text {max }}$ (b) & 20.5 & 20.6 & 20.4 & 20.8 & 21.2 & 21.7 & 21.9 & 22.0 & 22.1 \\
\hline $\mathrm{T}_{\min }(\mathrm{c})$ & 19.1 & 19.4 & 19.6 & 19.1 & 18.7 & 18.5 & 18.4 & 18.4 & 18.3 \\
\hline $\mathrm{T}_{\mathrm{a}}^{(\mathrm{d})}$ & 19.8 & 20.0 & 20.0 & 19.8 & 19.9 & 20.0 & 20.0 & 20.0 & 20.0 \\
\hline $\mathrm{SD}^{(\mathrm{e})}$ & 0.3 & 0.3 & 0.2 & 0.5 & 0.9 & 1.2 & 1.3 & 1.4 & 1.4 \\
\hline $\mathrm{LA}^{(\mathrm{f})}$ & 84 & 86 & 100 & 48 & 21 & 13 & 13 & 13 & 14 \\
\hline $\mathrm{d}_{\mathrm{TH}}{ }^{(\mathrm{g})}$ & 54 & 58 & 94 & 139 & 187 & 235 & 284 & 334 & 383 \\
\hline
\end{tabular}

${ }^{a} \mathrm{~d}_{\mathrm{HC}}=\mathrm{HC}$ depth in $\mathrm{mm} .{ }^{\mathrm{b}} \mathrm{T}_{\max }=$ maximum temperature in ${ }^{\circ} \mathrm{C} .{ }^{\mathrm{c}} \mathrm{T}_{\min }=$ minimum temperature in ${ }^{\circ} \mathrm{C} .{ }^{\mathrm{d}} \mathrm{T}_{\mathrm{a}}=$ average temperature in ${ }^{\circ} \mathrm{C} .{ }^{\mathrm{e}} \mathrm{SD}=$ standard deviation in ${ }^{\circ} \mathrm{C}$. ${ }^{\mathrm{f}} \mathrm{LA}=$ level of achievement in percentage. ${ }^{\mathrm{g}} \mathrm{d}_{\mathrm{TH}}=$ distance from control point to $\mathrm{HC}$ in $\mathrm{mm}$.

range 19.5 to $20.5^{\circ} \mathrm{C}$, i.e. in the reference temperature $\left(20^{\circ} \mathrm{C}\right)$, with a range of variation of $\pm 0.5^{\circ} \mathrm{C}$.

Two well-differentiated behaviors are observed for the HC buried at depths between 50 and $150 \mathrm{~mm}$ and for the HC buried at depths between 300 and $450 \mathrm{~mm}$. An intermediate behavior is found for the HC buried at 200 to $250 \mathrm{~mm}$ depths. When the $\mathrm{HC}$ is buried in the surface layers, T-70 fluctuates between $19{ }^{\circ} \mathrm{C}$ and $21{ }^{\circ} \mathrm{C}$, whereas in deeper substrate layers, fluctuation increases up to values between $18{ }^{\circ} \mathrm{C}$ and $22{ }^{\circ} \mathrm{C}$. The mean values for $\mathrm{T}-70$ come nearer to the reference temperature when the $\mathrm{HC}$ is buried in the bottom layers of the substrate, but the standard deviation is close to $1.5^{\circ} \mathrm{C}$. Conversely, when the $\mathrm{HC}$ is buried in the upper layers, the standard deviation does not exceed $0.3{ }^{\circ} \mathrm{C}$.

The level of achievement of the reference temperature is dependent upon the distance between the control point and the heating element. Accordingly, the levels of achievement of the reference temperature are very high for a $\mathrm{HC}$ buried in the surface layers $(84 \%-100 \%$ ) and very low for a $\mathrm{HC}$ buried in the bottom layers $(13 \%-14 \%)$. Yet, the level of achievement of the reference temperature is also dependent on distance to substrate surface. For this reason, the HC depth that provides the best level of achievement of the reference temperature is not the depth nearest to the control point (Table 4), but a depth of $150 \mathrm{~mm}$, where the level of achievement amounts to $100 \%$.

Overall Analysis of all HC depths - The increase in the heating cable depth causes an almost linear increase in HC daily average temperature from a depth of 100 $\mathrm{mm}$, at a rate of $2.6{ }^{\circ} \mathrm{C}$ for every $50 \mathrm{~mm}$ (Figure 6). The maximum temperature values follow a similar trend and fluctuate between $31.4{ }^{\circ} \mathrm{C}$ and $54.5{ }^{\circ} \mathrm{C}$. Average daily temperature at the control point $(\mathrm{T}-70)$ is close to the target temperature, $20{ }^{\circ} \mathrm{C}$, and ranges $19.8{ }^{\circ} \mathrm{C}$ to $20.0^{\circ} \mathrm{C}$ for the configurations with the $\mathrm{HC}$ buried at 50 and 150 $\mathrm{mm}$ depths. Average daily temperature in the root zone increases steadily from $19.6{ }^{\circ} \mathrm{C}$ for the $\mathrm{HC}$ buried at 50 $\mathrm{mm}$ depth up to a peak of $21.8{ }^{\circ} \mathrm{C}$ at the $200 \mathrm{~mm}$ depth. For greater HC depths, average daily temperature in the root zone becomes more stable, with values around 21.6 ${ }^{\circ} \mathrm{C}$. Average daily temperatures at positions T1 and T2 fol-

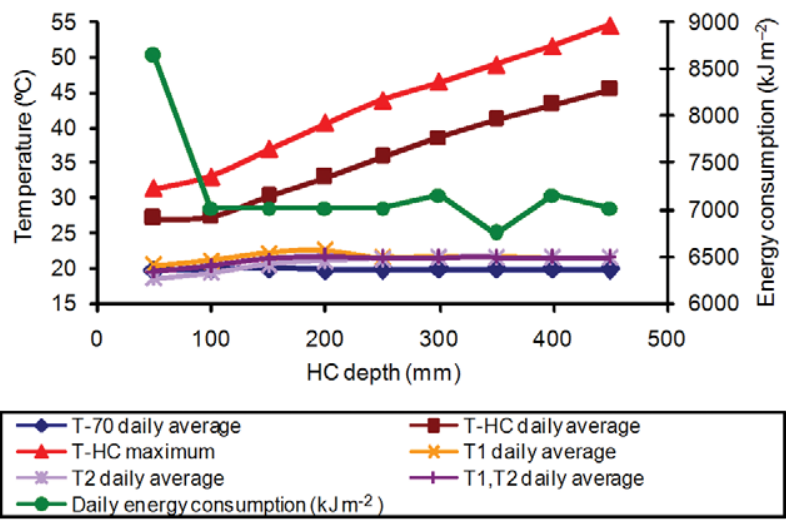

Figure 6-Temperatures in the root zone and on the HC, and daily energy consumption of the $\mathrm{HC}$ for different $\mathrm{HC}$ depths.

low a similar evolution, with higher temperatures at T1 than at T2. The temporal variations of the temperatures at T1 are higher than at T2. The differences observed between both positions are dependent upon the depth of installation of the HC. Accordingly, when the HC is buried at depths between 50 and $200 \mathrm{~mm}$, the differences observed for average daily temperatures fluctuate between $2.0^{\circ} \mathrm{C}$ and $1.5{ }^{\circ} \mathrm{C}$ respectively. For greater $\mathrm{HC}$ depths, temperatures at T1 and T2 rapidly converge, with differences in average daily temperatures of $0.2{ }^{\circ} \mathrm{C}$ at $250 \mathrm{~mm}$ and negligible differences at greater depths.

The energy consumption of the heating element is dependent upon depth, such that the highest consumption $\left(8640 \mathrm{~kJ} \mathrm{~m}^{-2}\right)$ is observed for the HC buried at the $50 \mathrm{~mm}$ depth. At greater depths, energy consumption is very similar, in the range 6,750 to $7,155 \mathrm{~kJ} \mathrm{~m}^{-2}$, and does not show a fixed performance trend with the increase in depth. The most efficient depth of installation is $350 \mathrm{~mm}$, with a daily consumption of $6,750 \mathrm{~kJ} \mathrm{~m}^{-2}$ and an average temperature of $21.6^{\circ} \mathrm{C}$ in the root zone. By comparing these values with the values of average daily temperature in the root zone, the HC depth of $200 \mathrm{~mm}$ reaches the highest value $(21.8$ ${ }^{\circ} \mathrm{C}$ ) with the modal consumption of $7,020 \mathrm{~kJ} \mathrm{~m}^{-2}$. Therefore the optimal ratio of depth to spacing of the cable placement is 1 . 


\section{Conclusions}

The average daily temperatures of the root zone are near to the $20^{\circ} \mathrm{C}$ preset temperature for all the tested $\mathrm{HC}$ depths, which is a suitable temperature for most crops. With the HC buried in the root zone (up to a depth of $200 \mathrm{~mm}$ ), the spatial and temporal uniformity of temperatures improves and control is most effective. However, burying the HC in the top layers of the substrate causes high energy consumption because of heat losses through the substrate surface (up to $28 \%$ ). Thus, burying the HC in the bottom layers is more efficient but involves storing a large amount of heat in the bottom layers of the substrate. Because that heat hardly reaches the root zone, the most efficient depth of installation is $350 \mathrm{~mm}$.

\section{References}

Ahmed, A.E.; Hamdy, M.Y.; Roller, W.L.; Elwell, D.L. 1983. Technical feasibility of utilising reject heat from power stations in greenhouses. Transactions of the American Society of Agricultural Engineers 26: 200-206.

ANSYS. 2001. ANSYS 6.0 Documentation: Version 6.0. ANSYS, Canonsburg, PA, USA.

Boulard, T.; Razafinjohany, E.; Baille, A. 1989a. Heat and water vapour transfer in a greenhouse with an underground heat storage system. I. Experimental results. Agricultural and Forest Meteorology 45: 75-184.

Boulard, R.; Razafinjohany, E.; Baille, A. 1989b. Heat and water vapour transfer in a greenhouse with an underground heat storage system. II. Model. Agriculture and Forest Meteorology 45: 185-194.

Campbell, G.S.; Jungbauer, J.D.; Bidlake, W.R.; Hungerford, R.D. 1994. Predicting the effect of temperature on soil thermalconductivity. Soil Science 158: 307-313.

De La Plaza, S.; Benavente, R.; García, J.; Navas, L.; Luna, L.; Durán, J.; Retamal, N. 1999. Modelling an optimal design of an electric substrate heating system for greenhouse crops. Journal of Agricultural and Engineering Research 73: 131-139.

De Vries, D.A. 1963. Thermal properties of soils. p. 210-235. In: van Wijk, W.R. ed. Physics of plant environment. Amsterdam: North Holland Publishing Company, The Netherlands.

Dodd, I.C.; He, J.; Turnbull, C.G.N.; Lee, S.K.; Critchley, C. 2000. The influence of supra-optimal root-zone temperatures on growth an stomatal conductance in Capsicum annuum $L$. Journal of Experimental Botany 51: 239-248.
Fernandez, M.D.; Rodriguez, M.R.; Maseda, F.; Velo, R.; Gonzalez, M.A. 2005a. Modelling the transient thermal behaviour of sand substrate heated by electric cables. Biosystems Engineering 90: 203-215.

Fernandez, M.D.; Rodriguez, M.R.; Maseda, F.; Velo, R. 2005b. Validation of temperature simulation based on finite element analysis in substrates heated by electric cable. Transactions of the American Society of Agricultural Engineers 48: 1241-1251.

Fernandez, M.D.; Rodriguez, M.R. 2006. Application of a heat transfer model for heated substrates in greenhouses to the dimensioning of spacing between electric heating cables. Biosystems Engineering 94: 573-585.

Fernandez, M.D.; Rodriguez, M.R.; Diaz, F. 2007. Modeling heat transfer in substrates heated by electric cable depending on heating cable spacing. Transactions of the American Society of Agricultural and Biological Engineers 50: 607-614.

Gent, M.P.N.; Ma, Y.Z. 2000. Mineral nutrition of tomato under diurnal temperature variation of root and shoot. Crop Science 40: 16291636.

Jury, W.A.; Gardner, W.R.; Gardner, W.H. 1991. Soil Physics. Wiley, New York, NY, USA.

Kurpaska, S.; Slipek, Z. 1996. Mathematical model of heat and mass exchange in a garden subsoil during warm-air heating. Journal of Agricultural and Engineering Research 65: 305-311.

Kurpaska, S.; Slipek, Z. 2000. Optimization of greenhouse substrate heating. Journal of Agricultural and Engineering Research 76: 129-139.

Mortesen, L.M.; Gislerod, H.R. 1996. The effect of root temperature on growth, flowering, and vase life of greenhouse roses grown at different air temperatures and $\mathrm{CO}_{2}$ concentrations. Gartenbauwissenschaft 61: 211-214.

Rikbost, K.; Boersma, A.L.; Mack, H.J.; Schmisseur, W.E. 1975. Yield response to soil warming. Agronomy Journal 67: 733-745.

Rodriguez, M.R.; Fernandez, M.D.; Maseda, F.; Velo, R.; Gonzalez, M.A. 2004. Electrical wire heating in sand substrates: Influence of depth and spacing on power per unit length. Biosystems Engineering 89: 187-195.

Roper, T.R.; Krueger, A.R.; DeMoranville, C.J.; Vorsa, N.; Hart, J.; Poole, A.P. 2004. Rate of ammonium uptake by cranberry (Vaccinium macrocarpon ait.) vines in the field is affected by temperature. Hortscience 39: 588-590.

Received May 14, 2010

Accepted March 14, 2011 